\title{
Massage Therapy and Canadians' Health Care Needs 2020: Proceedings of a National Research Priority Setting Summit
}

\author{
Trish Dryden, M.Ed, RMT, ${ }^{*}$ Bryn Sumpton B.Sc.N., ${ }^{2}$ Stacey Shipwright BA, RMT, ${ }^{1}$ \\ Janet Kahn PhD, EdM, LMT, ${ }^{3}$ Barbara (Findlay) Reece, RN, BSN ${ }^{4}$ \\ ${ }^{1}$ Research and Corporate Planning, Centennial College, Toronto, ON, Canada, ${ }^{2}$ Registered Massage Therapists' Association \\ of Ontario, Etobicoke, ON, Canada, ${ }^{3}$ Department of Psychiatry, University of Vermont, Burlington, VT, USA, \\ ${ }^{4}$ Independent Consultant, White Rock, BC, Canada
}

Background: The health care landscape in Canada is changing rapidly as forces, such as an aging population, increasingly complex health issues and treatments, and economic pressure to reduce health care costs, bear down on the system. A cohesive national research agenda for massage therapy (MT) is needed in order to ensure maximum benefit is derived from research on treatment, health care policy, and cost effectiveness.

Setting: A one-day invitational summit was held in Toronto, Ontario to build strategic alliances among Canadian and international researchers, policy makers, and other stakeholders to help shape a national research agenda for MT.

Method: Using a modified Delphi method, the summit organizers conducted two pre-summit surveys to ensure that time spent during the summit was relevant and productive. The summit was facilitated using the principles of Appreciative Inquiry which included a "4D" strategic planning approach (defining, discovery, dreaming, designing) and application of a SOAR framework (strengths, opportunities, aspirations, and results).

Participants: Twenty-six researchers, policymakers, and other stakeholders actively participated in the events.

Results: Priority topics that massage therapists believe are important to the Canadian public, other health care providers, and policy makers and massage therapists themselves were identified. A framework for a national massage therapy (MT) research agenda, a grand vision of the future for MT research, and a 12-month action plan were developed.

Conclusion: The summit provided an excellent opportunity for key stakeholders to come together and use their experience and knowledge of MT to develop a much-needed plan for moving the MT research and professionalization agenda forward.

KEY WORDS: massage therapy; research; Delphi method; methodology; conference

\section{INTRODUCTION}

The health care landscape in Canada is changing rapidly and will continue to change over the next two decades as forces, such as an aging population, increasingly complex health issues and treatments, and economic pressure to reduce health care costs, bear down on the system ${ }^{(1)}$. Where does massage therapy (MT) fit in this changing environment, and what role can it play in providing a safe and effective option for addressing Canadians' health care needs? Those questions are likely best addressed through quality research. Clinical practice that is based on evidence is the best way to deliver care with the most cost-effective use of available resources ${ }^{(2)}$.

Tremendous progress has been made in the field of MT research; however, researchers suggest that there is still a long way to go, and both the quantity and the quality of MT research need to improve ${ }^{(3)}$. Research in the field of massage therapy is still in a relatively early stage when compared to other professions and this is partly due to a lack of research infrastructure and a research tradition that has been slow to develop. There is more work to be done in educating practitioners so that they become comfortable reading and applying the MT literature ${ }^{(4)}$. Another reason for limited research uptake might be that the profession has not yet investigated topics that massage therapists view as important to the profession ${ }^{(5)}$. If massage therapists wish to provide the best possible care to their clients and want to see the profession evolve, more rigorous research is needed ${ }^{(6)}$. A cohesive national research agenda for massage therapy is needed to ensure maximum benefit is derived from research on treatment and cost effectiveness, and to inform health care policy. Developing such an agenda may also advance professionalization of massage therapy across Canada $^{(7)}$. On November 2, 2012, in response to these issues, a one-day invitational summit was held to bring together a knowledgeable and invested group of 26 Canadian and international MT researchers, policy makers, and other stakeholders to create a vision for a national massage therapy research agenda. 
The summit was conceived by organizers Trish Dryden, Associate Vice-President, Research and Corporate Planning, Centennial College, and Bryn Sumpton, Executive Director and CEO, Registered Massage Therapists'Association of Ontario. The summit built on current literature highlighting the need for massage therapy research, as well as previous national and international massage research agenda-setting initiatives, such as the three-day conference held by the Massage Therapy Foundation in 1999. In addition, Stacey Shipwright, Research Analyst, Centennial College, and Janet Kahn, Research Assistant Professor, Department of Psychiatry, University of Vermont, were asked by the organizers to participate in a series of pre-summit teleconferences, along with summit facilitator, Barb (Findlay) Reece, senior health care consultant, to develop the surveys, conduct content analysis on the data, attend the summit, and contribute to the final meeting report and this paper. Organized as a pre-symposium event for the 7th IN-CAM Research Symposium 2012, the summit capitalized on the biannual IN-CAM research gathering being held in the Leslie Dan Pharmacy Building on the University of Toronto campus.

\section{METHODS \& PARTICIPANTS}

The primary aim of the summit was to build strategic alliances and shape future massage therapy research efforts. Jointly organized by Centennial College and the Registered Massage Therapists' Association of Ontario, it was primarily sponsored by the Dr. Rogers Prize for Excellence in Complementary and Alternative Medicine, with additional financial support from the Registered Massage Therapists' Association of Ontario, the College of Massage Therapists of Ontario, and the Newfoundland and Labrador Massage Therapists' Association. Other organizations, including the Massage Therapists' Association of British Columbia and several academic institutions, provided support by covering travel expenses for their representatives. Typically, summit proceedings include abstracts from participant presentations. This summit was organized differently; participants completed surveys prior to the summit and then engaged in facilitated discussions when they met for the one-day event. The proceedings from the summit include survey results, a framework for a national massage therapy research agenda, a grand vision of the future of MT, and a 12-month action plan, all of which are reported here.

\section{Summit Participants}

Convenience sampling was used to select participants for the summit. Participants all had a background in Massage Therapy research and included: representatives from two of the Canadian regulatory
Colleges, representatives from provincial professional associations, researchers from the United States who had an understanding of the Canadian massage context, members of academia, government and policy representatives, and practitioners.

\section{Pre-summit Activities}

A modified Delphi process was used to prepare for the summit. The Delphi technique is a method for consensus-building on real-world issues with a group of experts and is used widely across disciplines ${ }^{(8)}$. Prior to the summit, workshop participants were invited to complete two online surveys. The participants were advised that their responses to the surveys would be anonymous and that only aggregated information from the surveys would be shared with summit participants. The purpose of the surveys was to encourage participants to think deeply about massage therapy research before attending the summit, to ensure that time spent during the summit was as relevant and productive as possible. The first survey asked participants to prioritize research topics, and the second survey helped to refine participants' priority topics. The survey results enabled summit participants to engage from a shared and current understanding of the MT community's priorities, perspectives, and readiness to build a national research agenda.

\section{First Survey}

The first survey was sent out eight weeks prior to the meeting, and the focus of Part A was to:

- Identify the main goals of massage therapists today that could, or should, be informed by research;

- Identify questions or concerns the Canadian public, other health care professionals, and/or policymakers in the Canadian health care system have about massage therapy that could be answered by massage therapy research;

- Consider how trends in Canadian health care delivery might align with a national massage therapy research agenda; and

- Identify types of research that could strategically advance massage therapist goals and/or address stakeholder concerns.

Part B included five general categories of massage therapy research, derived from the MT literature. Participants were asked to identify examples of research that they thought were most relevant and important to massage therapists and other stakeholders of massage therapy research, and best able to advance the goals of the massage therapy profession. These research categories were 'basic science', 'clinical', 'health services', 'the profession', and 'socio-cultural knowledge'. Refer to Table 1 for 
Table 1. Study Types to Advance the Goals of the MT Profession (Part B).

BASIC SCIENCE

-Studies that examine questions of mechanism (psychological and physiological) of MT

-Studies that map the systemic effects of massage therapy

-Studies that map the local effects of massage therapy

HEALTH SERVICES/TRANSLATIONAL

-Effect of massage therapy on reducing anxiety and/or depression

-Studies that examine massage in comparison with other treatments

-Primary prevention studies (e.g. workplace wellness, prevention of congestive heart failure)

-Effects of access to massage therapy on under-served populations [added in round two]

\section{CLINICAL}

-Multidimensional studies that assess several types of outcomes to make the best use of resources e.g. selfreport of symptom relief, practitioner observed behavior and biochemistry.

-Studies that determine the safety of using massage therapy in specific populations or for specific conditions

-Studies that examine "optimal doses" of massage therapy

-Studies that compare the effectiveness of massage therapy to other interventions [added in round two]

-Studies that examine the psychological/psychosocial effects of massage therapy [added in round two]

ABOUT THE PROFESSION

-Research on the optimal education and training of a massage therapist

-Studies of the profession of massage therapy e.g. how excellence is defined

-Perceptions of massage therapists by self and others

-Role of massage therapists as health care providers on teams in community health settings, with specific patient populations [added in round two]

\section{SOCIO-CULTURAL KNOWLEDGE}

-Perceptions of massage therapy/massage therapists by other health professionals

-Public perceptions about massage therapy/massage therapists -Studies on the nature of the therapeutic encounter, including exploration of placebo, nonspecific effects, etc.

-Massage therapist knowledge of massage therapy evidence base; other health care providers "knowledge of massage therapy evidence-base; policy makers" knowledge of massage therapy evidence base [added in round two]

The table indicates the prioritization of responses from a list of options under five broad research categories: basic science, clinical, health services/translational, the MT profession, and socio-cultural knowledge. The most highly prioritized response appears in bold.

descriptions of each category. Participants were asked to rank topics that they considered were important and to add any topics they felt were missing from the list. Descriptive statistics (frequencies and means) were calculated for the survey data, and open-ended comments were analyzed using a content analysis approach. Results from the first survey were reviewed and interpreted by the organizers and facilitator, and the results were used to inform the second round of the Delphi process.

\section{Second Survey}

A second survey was sent out one month after the first, three weeks prior to the meeting. Choices made on the first survey were re-ordered on the second survey according to the aggregate degree of importance participants assigned topics in the first round. Any new suggestions from participants were added to the bottom of the list of response options. Participants were asked to rank-order their top choices, and then decide if any of the 'new choices' were important enough to move to the top of the list and be considered for discussion at the summit. As with the first survey, descriptive statistics were calculated for the survey data, and open-ended comments were analyzed using a content analysis approach. This iterative process served to confirm priorities highlighted in the first survey and provided the summit organizers with a solid foundation on which to build a summit agenda and activities that would be meaningful for the participants.

\section{Survey Results}

All participants $(n=26)$ completed the pre-summit surveys within the requested timelines. Table 2 includes results from the two surveys. The table 
Table 2. Summit Participant Perceived Priorities, of Questions, Goals or Trends, to Inform a Vision for a National Research Agenda (Part A)

CONCERNS OF THE CANADIAN PUBLIC

-What health concerns can massage therapy help with/ not help with?

-How many treatments will I need and how much will it cost? -Is it always safe?

-How does massage therapy compare to other available therapies for treating my condition? [added in round two]

\section{CONCERNS OF HEALTH CARE PROVIDERS AND POLICY MAKERS \\ -Is massage therapy safe? For which conditions and popula- tions? Under what circumstances?}

-Is massage therapy a cost-effective alternative to treatments we currently provide?

-How does massage therapy treatment integrate with or add value to the patient's other treatment plans and providers?

-How does massage therapy fit with models of integrative, patient-centered care? [added in round two]

\section{MASSAGE THERAPIST GOALS \\ -Massage therapists want to be valued as bona fide members of interprofessional health care teams and/or collaborations}

-Massage therapists want to understand more clearly how and why their work is effective or ineffective

-Massage therapists want more people to seek regular massage for health maintenance and wellbeing

-Massage therapists want to demonstrate that research and education leads to better outcomes for patients. [added in round two]

TRENDS IN CANADIAN HEALTH CARE

-An aging population that aspires to a high quality of life

-Reducing health care costs through innovative health human resource strategies

-Introducing policy to promote healthy lifestyle and disease prevention

-Reducing health care costs through innovative service delivery methods [added in round two]

The table includes the most highly prioritized stakeholder questions, goals or trends as perceived by the summit participants. It also includes the most highly prioritized "new choice" for each category identified in the second round prioritizing survey. The top priority response appears in bold in each category.

includes the most highly prioritized stakeholder questions, goals or trends that participants think should inform the vision for a national research agenda. It also includes the most highly prioritized "new choice" for each category identified in the second survey. The top priority response appears in bold in each category.

Respondents showed a high degree of alignment as a group in prioritizing issues that are important to Canadian massage therapists. While high-priority items are reported in the table, the top priority items (those appearing in bold) were selected as important by $90 \%$ or more of the respondents. The items also generated a wide variety of comments, specific research questions, and other creative suggestions for shaping a national research agenda

It was interesting to note the research priorities that summit participants believed were of most importance to the broader stakeholders of massage therapy research, in contrast to their own priorities as massage therapists. Participants believe that the Canadian public, health care providers, and policymakers would be most interested in new knowledge about the safety and effectiveness of massage therapy, and which specific populations and conditions would benefit most from treatment. They thought that these priorities would take precedence over research on cost or 'fit' with other models of care.

Survey responses related to MT's own goals indicated that massage therapists think they have a good understanding of the effectiveness of their work and would like to see more research conducted around role development and strengthening MT relationships within interprofessional teams. The participants also indicated that research regarding the utility and benefits of massage therapy in an aging Canadian population should take precedence over cost reduction in human health services and innovations in service delivery.

Part B of both surveys asked participants to prioritize responses from a list of options under five broad research categories: basic science, clinical, health services/translational, the MT profession, and sociocultural knowledge (Table 1). As in the first round of the survey, the most highly prioritized response appears in bold.

The results from the Part B categories suggest that for participants, the mechanism of MT and how it works takes priority over the impact of MT on clinical outcomes. Impact, however, is still important and participants indicated that building the evidence base on the impact of MT on depression and anxiety, for example, is still very much needed. They would like to see richer, more complex studies conducted where triangulation of methods and sources is used to gain a complete understanding of processes and outcomes. Research on optimal education and training of a massage therapist was also identified as a top priority.

It is interesting to note that there was less agreement for topics identified in the clinical, the sociocultural, and the 'about the profession' categories. None 
of the items presented in the clinical and sociocultural categories achieved $80 \%$ consensus, and just one item in the 'about the profession' category, related to education, achieved a rating of $88 \%$. The issues presented in those categories were viewed as less urgent at this time.

\section{The Summit}

The participants enjoyed a networking breakfast prior to the summit, which began at 9:00 a.m. The day was organized around a detailed, yet flexible, agenda that left room for adjustments as the work unfolded. The agenda was structured around the following main goals:

1. Propose a framework of questions to be used during the summit to build the vision for a national massage therapy research agenda.

2. Confirm the framework as the basis for a research agenda and generate ideas for relevant, powerful studies or collaborative research initiatives.

3. Explore how research opportunities can be created, and generate ideas for initiating activity.

4. Articulate the vision for a national massage therapy research agenda and develop a 12-month action plan for moving this initiative forward.

The summit was guided by an expert facilitator, Barb (Findlay) Reece, who was hired by the organizers. Reece facilitated the summit using an Appreciative Inquiry approach she had adapted ${ }^{(9)}$. This approach includes a "4D” strategic planning approach (defining, discovery, dreaming, designing). The first half of the day was "generative", in that all ideas were solicited and encouraged without prioritization. From an Appreciative Inquiry perspective, these represented the "defining" and "discovery" stages of the "4D" strategic planning process.

\section{Summit Outcomes}

\section{A framework for a national MT research agenda}

The final framework of questions that participants believed would best shape a national research agenda for massage therapy included:

- What are the main shared goals of Canadian massage therapists?

- What questions/concerns does the Canadian public have about massage therapy?

- What questions/concerns do other health professionals have about massage therapy?

- What questions do researchers (especially from outside of the massage therapy profession) have about engaging in massage therapy research?

- What questions do educators have about teaching massage therapists?
- What questions/concerns do policy-makers/ research funders have about massage therapy?

- Where is there opportunity to align a research agenda with provincial massage therapy organizations and regulators, national health care goals, consumer interests, and funders current research priorities?

The second half of the day focused more on the "dreaming" and "designing" phases, and on getting the group to SOAR: capturing their strengths, concrete opportunities, aspirations, and (proposed) results. Through this facilitated, prioritizing process the group was able to articulate both a "grand vision" for massage therapy and a 12-month action plan.

\section{Summit outcome: the grand vision}

In the dream phase of appreciative inquiry, a large group activity towards the end of the summit, participants were asked to imagine the following scenario and contributed to a grand vision for MT through a large group-facilitated discussion.

It is five years from today, and you, as the discipline of massage therapy, have been incredibly successful in your efforts to establish and carry out a national research agenda for massage therapy in Canada. How will your world be different today than it was five years ago? What will be in place; what will be happening; what will you see, feel or hear that is different now?

Massage therapy is a viable, useful health profession that retains its unique identity and history, aligning with, but not "absorbed by", the mainstream biomedical community. Progress has been made in the various branches of $\mathrm{MT}$, research, practice, and education, and strategic alliances have been formed.

\section{Research}

- A well-funded, broadly recognized, and wellrespected Canadian Massage Therapy Research Foundation is established that supports four research chairs and two bachelor-level programs in massage therapy.

- There is national buy-in and collaboration across the discipline for a national research agenda that includes increased research literacy, research capacity, and professional networking opportunities.

- Knowledge translation - the synthesis, dissemination and exchange of MT knowledge - is built into all MT research.

- At least three Cochrane reviews are published that do not emphasize that more research is needed.

- Viable career paths exist for massage therapist researchers in academia and across interdisciplinary organizations.

- There is a new, accessible, online repository, developed as a tool to support members of a massage therapy practice-based research network and other research initiatives. 


\section{Practice}

- There is a National Adverse Events Database for Massage Therapy and data are widely available.

- Regulatory bodies have few misconduct hearings.

- Massage therapy is regulated in all Canadian provinces and territories.

- Massage therapy clinics are more frequently located in interprofessional settings and massage therapists are more frequently integrated into interprofessional health care teams.

- All massage therapists know how to use mobile applications to access best practice guidelines and best evidence, such as databases, journals, and review articles, to inform their practice.

- Massage therapists are talking knowledgeably and enthusiastically about treatment outcomes and about collaborating on research. MT clinicians know how to use, record, and interpret valid outcome measures. All massage therapists read clinical case reports, and many have written one themselves.

- Massage therapy is a standard part of oncology care and pain management.

- Community-based care teams employ salaried massage therapists who provide patient education, as well as treatments.

- There is a national/international "shared communication forum" for massage therapists to come together as peer contributors.

- Massage therapists learn and use "meta-competencies ${ }^{\text {ee }}$ of which more conventionally perceived modalities and skills are component parts.

- Massage therapists are able to describe what they do, without relying on the word "intuition."

\section{Education}

- MT education has an academic base, and embraces technology-enabled learning, interprofessional practice, and research in order to prepare massage therapists for collaborative, patientcentered care that is integrated into health care delivery in new ways.

- Research literacy is a national standard for massage therapists and part of all core curricula.

- On entry to practice, all massage therapists can easily and readily describe what massage therapy is with reference to the evidence.

- There is a pan-Canadian strategy in effect for recognizing and bridging to practice internationally trained massage therapists.

\section{Society/Outreach}

- Health care policy and legislation in Canada is informed by relevant MT research.

- The Discovery Channel features massage therapy case studies in its programming.

- Organizations such as Telehealth Ontario make reference to massage therapists to provide online/ phone patient care.
- As a discipline, we have strategic two-way open lines of communication with all levels of government about public priorities.

- Canada has an EHR (electronic health record) that has been designed to capture data and treatment information that is relevant to and includes massage therapy.

The framework for the national agenda for the future is broad and comprehensive: it accounts for multiple stakeholders, the public, MTs, and other health professionals. It accounts for different branches within the discipline: clinicians, educators, and researchers. Finally, it is collaborative and strategic_-it acknowledges the need to align with other groups in order to accomplish goals. The vision indicates that the summit participants are bold, visionary, and have a clear idea of where they would like the profession to be in five years' time. The vision suggests that MT must be an evidence- based profession, and that considerable work needs to be done in education and practice to achieve that goal. It also means much work is needed to build a strong foundation of evidence for practice. Individual research projects need to be supported and conducted; however, it is equally important that innovative use of technology be made to support networking and collaboration. Moving the MT national research agenda forward will depend, in part, on knowledge transfer getting input from a range of stakeholders at the research planning stage, and then sharing research results in a way that is meaningful for stakeholders and decision-makers.

\section{Summit outcome: twelve month action plan}

Building a national research agenda is an ambitious initiative that, by necessity, takes place over time in several phases. This summit was intended to launch that process, not complete it. For example, the decision to have participating experts identify questions or concerns that other stakeholder groups have about massage therapy in the pre-summit surveys was made to facilitate the gathering of best information possible within the timeframe and budget of the project. Care was taken during the meeting to organize participants into breakout groups according to the stakeholder groups they identified most closely with, or had most regular interaction with. While we don't imagine that stakeholders themselves, given the opportunity, would have responded hugely differently, they may have assigned different priority to the questions and concerns identified. Participants acknowledged these types of process limitations and noted that, in subsequent phases of developing a national research agenda, it would be important to solicit feedback directly from other stakeholder groups and confirm any assumptions generated during the summit.

The dream phase was important because it contributed to the creation of a broad, shared vision of 
MT as a profession and what "advancement of the profession" might look like. From a vision, it is possible to start identifying a set of indicators that can be measured or observed through research towards the goal of answering stakeholder questions identified earlier in the process.

The summit concluded with the collective development of a 12-month Action Plan. Participants were asked to identify actions and volunteer themselves or organizations to keep the process moving. To be included, actions had to meet the following feasibility criteria:

i) build on strengths and opportunities the group have identified;

ii) are not contingent on a large source of new funding;

iii) are led willingly by someone/some organization; and

iv) can be achieved in 12 months.

\section{Activities proposed for a twelve-month action plan (not prioritized)}

- Form a special interest group for MT research under the umbrella of IN-CAM (Canadian interdisciplinary network for complementary and alternative medicine research)—an MT Special Interest Group (SIG)

- Conduct a national survey to gather information about the conditions most commonly treated by MT

- Convene a summit with MT leaders from across Canada with the goal of forming a reference point for the discipline

- Evaluate potential outcome measures and list most practical use in MT research

- Strategize around Post-secondary Strategic Mandate Agreements (Ontario government and post-secondary institution-specific) re: relevance and alignment with national $\mathrm{MT}$ research agenda

- Conduct a needs assessment of Canadian MT educators on the subject of teaching about MT research; build research capacity among MT students, especially those interested in research and develop skills in measurement and evaluation

- Propose the process and requirements (expertise, resources, etc.) for developing an Adverse Event Database for MT

- Recruit a minimum of 15 schools to generate cases for inclusion in a Case Study Repository

The summit was closed with a round-table exchange of closing thoughts from participants. Many shared thoughts that the day had been both productive and inspiring and that they were motivated to support next steps. They felt that the 12-month action plan was feasible and, because it was clear and realistic, it would drive much-needed action over the next year. Most participants expressed gratitude for the networking opportunity that this initiative afforded.

\section{Next Steps}

Summit participants agreed to immediately start organizing to work on several of the actions outlined in the plan; some of this work has already started. A workshop to explore interest and feasibility of creating a national special interest group for massage therapy research, held on November 3, 2012 during the IN-CAM symposium, was well-attended and the IN-CAM, MT SIG has been created and two working groups are well underway (http://www.incamresearch .ca/index.php?id=133,699,0,0,1,0). The plan is ambitious and it is essential. The plans to codify MT knowledge and establish databases for practice, the push to align with evidence-based practice, the plans to form connections with powerful groups and to seek recognition with the larger practice community are all important steps in gaining full professional status ${ }^{(10)}$. Given the potential for synergy and mutual benefit, ongoing dialogue and coordination of effort between groups is recommended. Outcomes of the summit will be the focus of future papers.

\section{CONCLUSION}

While there is still some way to go before MT has a solid research foundation for practice, the 2012 summit was an important step forward in achieving that goal. Priority topics that MTs believe are important to the Canadian public, other health care providers, and policy makers and MTs themselves were identified. A framework for a national MT research agenda, a grand vision for MT research, and a 12-month action plan were developed. The summit provided an excellent opportunity for key stakeholders to come together and use their experience and knowledge of MT to develop a much-needed plan for moving the MT research agenda forward.

\section{ACKNOWLEDGEMENTS}

The authors thank the individuals who participated in the 2012 invitation summit. Participants included: Alison Esser, College of Massage Therapists of British Columbia, Amanda Baskwill, Humber College, Andrea Burton, Monkeytree Creative, Ania Kania, IN-CAM, Antony Porcino, BC Cancer Agency \& UBC School of Nursing, Barbara (Findlay) Reece, Consultant, Beth Barberree, Massage Therapist, Bodhi Haraldsson, Massage Therapists' Association of British Columbia, Bryn Sumpton, Registered Massage Therapists' Association of Ontario, Cathy Fournier, Massage Therapist, Christopher Moyer, University of Wisconsin-Stout, CK Andrade, Physiotherapist and Consultant, Claudette Marie Warren, Newfoundland and Labrador Massage Therapists' Association, Corinne Flitton, College of Massage Therapists of Ontario, Debra Curties, Sutherland-Chan 
and Donelda Gowan-Moody, University of Saskatchewan, Janet Kahn, University of Vermont Full Circle Healing Center, Jennifer Lynch, Georgian College, Martha Menard, Sigma Applied Research, Pam Fitch, Algonquin College, Paul Clifford, Fleming College, Paul Finch, Conestoga College, Piroska Kennedy, Massage Therapist, Ruth Werner, Massage Therapy Foundation, Sara Sexton, Harmony Centre Inc., Stacey Shipwright, Centennial College, Susan Addario, College of Massage Therapists of British Columbia, Trish Dryden, Centennial College, and Wendy Hunter, Centennial College (Emeritus).

The authors also wish to thank the following sponsors: Dr. Rogers Prize for Excellence in Complementary and Alternative Medicine, Registered Massage Therapists' Association of Ontario, College of Massage Therapists of Ontario, and the Newfoundland and Labrador Massage Therapists' Association.

\section{CONFLICT OF INTEREST NOTIFICATION}

The authors are not aware of any conflicts of interest or potential conflicts of interest regarding the material in this manuscript. The funder of the study, The Dr. Rogers Prize for Excellence in Complementary and Alternative Medicine, had no role in the design of the study; in the collection, analysis, and interpretation of the data; in the writing of the resultant articles; or in the decision to submit this article for publication.

\section{COPYRIGHT}

Published under the CreativeCommons AttributionNonCommercial-NoDerivs 3.0 License.

\section{REFERENCES}

1. Leonard L. Canada's Aging Population and Public Policy: Statistical Overview. Publication No:2011-63-E. Ottawa, ON: Library of Parliament. Available from: http://www.parl.gc.ca/ content/lop/researchpublications/2011-63-e.htm Accessed April 102013.
2. Loiselle CG, Profetto-McGrath J, Polit DF, Tatano Beck C. Canadian Essentials of Nursing Research, 3rd edition. Philadelphia, PA: Lippincott Williams \& Wilkins; 2011.

3. Moyer CA, Dryden T, Shipwright S. Directions and dilemmas in massage therapy research: a workshop report from the 2009 North American research conference on complementary and integrative medicine. Int $J$ Ther Massage Bodywork. 2009;2(2):15-27.

4. Finch PM. The evidence funnel: highlighting the importance of research literacy in the delivery of evidence-informed complimentary health care. J Bodywork Mov Ther. 2007;11(1):78-81.

5. Porcino AJ, Boon HS, Page SA, Verhoef MJ. Exploring the nature of therapeutic massage bodywork practice. Int $J$ Ther Massage Bodywork. 2013;6(1):15-24.

6. Moyer CA, Rounds J, Hannum JW. A meta-analysis of massage therapy research. Psychol Bull. 2004;130(1):3-18.

7. Dryden T. Integrating massage therapy research and education, Chapter 18. In: Dryden T, Moyer CA, editors. Massage Therapy: Integrating Research and Practice. Champaign, IL: Human Kinetics; 2012. p. 211-221.

8. Hsu CC, Sandford BA. The Delphi technique: making sense of consensus. Practical Assessment, Research \& Evaluation. 2007;12(10). Available from: http://pareonline.net/pdf/ v12n10.pdf Accessed April 102013.

9. McKenna C, Daykin J, Mohr BJ, Silbert T. Strategic Planning with Appreciative Inquiry: Unleashing the Positive Potential to SOAR 2007. Available from: http://stickneyprofessionallearning .wikispaces.com/file/view/Appreciative+Inquiry+article.pdf Accessed December 5, 2013.

10. Smith DM, Smith, JM, Baxter D, Spronken-Smith R. The drive for legitimation of massage therapy in New Zealand. Int J Ther Massage Bodywork. 2013;5(4):21-29.

Corresponding author: Trish Dryden, M.Ed, RMT, Research and Corporate Planning, Centennial College, PO Box 631, Station A, Toronto, ON, Canada M1K 5E9

E-mail: tdryden@centennialcollege.ca 